\title{
Novel Use of Rituximab for Steroid-Dependent Nephrotic Syndrome in Children
}

\author{
Takahisa Kimata Masafumi Hasui Jiro Kino Tetsuya Kitao Sohsaku Yamanouchi \\ Shoji Tsuji Kazunari Kaneko
}

Department of Pediatrics, Kansai Medical University, Osaka, Japan

\begin{abstract}
Key Words
Rituximab - Steroid-dependent nephrotic syndrome . Minimal-change disease $\cdot$ Children
\end{abstract}

\begin{abstract}
Background: Though rituximab (RTX) is effective for childhood steroid-dependent nephrotic syndrome (SDNS), an established regimen does not exist. The relapses tend to occur when the peripheral blood B-cell count re-arises at 3 months upon single RTX infusion. This study was conducted to clarify whether the long-term remission of SDNS can be obtained by repeated RTX administrations. Methods: RTX was administered 4 times at 3-month intervals at $375 \mathrm{mg} / \mathrm{m}^{2} /$ time to 5 children with SDNS. The changes in the clinical indicators were analyzed. Results: The median (range) observation period was $6.3(0.9-8.4)$ years before RTX and 3.2 (1.93.8) years following the commencement of RTX. The changes in the clinical indicators were as follows (median and range): (1) annual number of relapses: before administration 1.4 (1.1-3.5) times/year, after administration 0.0 (0.0-0.0) times/year, and (2) median steroid dosage: before administration $0.80(0.23-0.96) \mathrm{mg} / \mathrm{kg} /$ day, after administration 0.00 $(0.00-0.00) \mathrm{mg} / \mathrm{kg} / \mathrm{day}$. All changes were significant at $\mathrm{p}<$ 0.05. Relapse occurred 3 times following the start of RTX (the period to relapse was $2.2,1.9$, and 2.3 years, respectively). No serious side effects were seen. Conclusions: Repeated RTX against SDNS in children may be a useful therapeutic option.
\end{abstract}

๑) 2013 S. Karger AG, Basel

\section{KARGER}

E-Mail karger@karger.com

www.karger.com/ajn

\section{Introduction}

Idiopathic nephrotic syndrome (NS) is one of the most frequent glomerular diseases in childhood. Although most cases respond to steroid treatment, approximately $40 \%$ of children with NS develop refractory NS, such as frequent-relapsing nephrotic syndrome (FRNS) or steroid-dependent nephrotic syndrome (SDNS) [1]. These patients are usually treated with immunosuppressants, such as cyclosporine A (CsA), cyclophosphamide (CPA), mizoribine (MZB) and mycophenolate mofetil (MMF). However, the immunosuppressants have significant adverse effects in children: chronic nephrotoxicity is a wellknown side effect of CsA $[2,3]$; because of the possibility of gonadal toxicity (azoospermia), CPA is recommended to be used within limited cumulative doses [4]; furthermore, MZB and MMF are still off-label for SDNS in Japan. Therefore, even if these immunosuppressants are effective, it is difficult to use these drugs for a long period for children. As a result, some patients continue to have relapses. Such patients often suffer from severe steroid toxicity, such as cataracts, obesity, osteonecrosis and growth failure.

Rituximab (RTX; anti-CD20 monoclonal antibody) has been successfully used to treat patients with refractory NS including SDNS in the last decade [5-16]. However, many patients are likely to relapse, consistent with the re-emergence of B-cell count $[5,14]$. Based upon re- 
cent data demonstrating that the peripheral B-cell count decreased for approximately 3 months following single RTX administration [17], we designed a protocol of repeated RTX administration for children with SDNS. The present study was conducted to clarify whether the longterm remission of SDNS can be obtained by the repeated administration of RTX and by maintaining a decreased peripheral blood B-cell count.

\section{Patients and Methods}

\section{Patient Population}

The patients enrolled in this study met the following criteria: (1) they were younger than 20 years old, (2) they had idiopathic NS, (3) the disease was SDNS despite conventional immunosuppressants, such as CsA, CPA, MZB, azathioprine (AZP) and MMF were being taken, (4) they did not have SRNS, and (5) they had no history of RTX treatment.

The definitions and criteria for NS, remission, relapse, frequent relapse, steroid dependency, and steroid resistance were those of the International Study of Kidney Disease in Children [18]: patients with two consecutive relapses of NS while receiving prednisolone (PSL) on alternate days or within 15 days of its discontinuation were defined as having SDNS; patients with two or more relapses within 6 months after initial therapy or four relapses in any 12 -month period were defined as having FRNS; patients with the inability to induce remission with 4 weeks of daily steroid therapy ( $60 \mathrm{mg} / \mathrm{m}^{2}$ BSA or $2 \mathrm{mg} / \mathrm{kg}$, max. $80 \mathrm{mg} /$ day) were defined as having SRNS [19]; relapse was defined as heavy proteinuria (3+ or $4+$ by dipstick for more than 3 consecutive days); complete remission was defined as the disappearance (negative by dipstick) of proteinuria.

Approval of the off-label use of RTX and of the study protocol was obtained from the institutional review boards of Kansai Medical University (No. 1118). All patients and their parents gave their written informed consent.

\section{Therapeutic Protocol}

Before the RTX infusions, we determined the patients' complete blood counts, biochemical parameters (total protein, albumin, blood urea nitrogen, creatinine, uric acid, alanine aminotransferase, aspartate aminotransferase, lactate dehydrogenase, serum levels of electrolytes, serum immunoglobulin (Ig) levels), CD19+ B-cell counts by flow cytometry, and titers of hepatitis B virus and hepatitis $\mathrm{C}$ virus. Chest radiographs and electrocardiograms were obtained, and echocardiography was also carried out because recent clinical case series reported that acute coronary syndromes, severe cardiac arrhythmia, and fatal interstitial pneumonia can be induced by RTX therapy [20-23]. After a patient obtained remission with PSL, we administered RTX intravenously at $375 \mathrm{mg} / \mathrm{m}^{2} \mathrm{BSA} /$ time (max. $500 \mathrm{mg} /$ time) every 3 months for a total of 4 times. In order to minimize infusion reactions, we gave the patients acetaminophen and cyproheptadine hydrochloride 30 min prior to the RTX infusions [17]. Patients were observed in the hospital for at least $24 \mathrm{~h}$ after RTX infusion. Chemoprophylaxis with sulfamethoxazole-trimethoprim was given during B-cell depletion to reduce the risk of Pneumocystis jirovecii infection [24].
Follow-Up

For all patients, clinical and laboratory parameters, including complete blood counts, biochemical parameters described before and CD19+ B-cell counts were monitored once every 3 months. PSL was tapered and discontinued after the first RTX infusions and MMF was administered (30-40 mg/kg/day) after 3 months from the final RTX infusions if parental informed consent was obtained. However, the detailed protocols for discontinuation of PSL or administration of MMF were left to doctors in charge.

Patients were followed up for at least 21 months after they had been given the first RTX infusions, that is, 12 months after the last RTX infusions. The frequency of relapses, steroid-free periods, and dosages of steroids were evaluated before and after the RTX treatment. B-cell depletion was defined as a CD19+ cell count $<10$ cells/ $\mathrm{mm}^{3}$ at any time, and B-cell re-emergence was defined as a CD19+ cell count $>10$ cells $/ \mathrm{mm}^{3}$.

\section{Statistical Analysis}

We used the Wilcoxon signed-rank test to compare the number of relapses, steroid-free periods, PSL dosages, B-cell counts, and serum Ig levels before and after RTX infusion. The level of statistical significance was set at $\mathrm{p}<0.05$.

\section{Results}

\section{Patients' Characteristics}

Five children ( 3 boys, 2 girls) with SDNS despite the use of multiple immunosuppressive agents were enrolled in this study. They were treated with repeated administrations of RTX at the Department of Pediatrics, Kansai Medical University Hirakata Hospital between August 2009 and April 2013. The clinical characteristics of the patients are summarized in table 1 . Renal biopsies revealed minimal change disease (MCD) in 4 patients and focal segmental glomerulosclerosis (FSGS) in 1 patient. At the time of RTX infusion, all patients suffered from severe steroid-dependent conditions and could not discontinue steroid usage under several immunosuppressants, such as CsA, MZB, AZP and MMF. The effects of severe steroid toxicity, such as short stature, obesity, osteoporosis, hypertension and cataracts, were observed in all of the patients.

The median age at the start of the RTX administration (range) was 14.4 (10.3-17.0) years. The median (range) observation period was $6.3(0.9-8.4)$ years before RTX administration and median (range) number of relapses before the commencement of RTX was 8 (3-12) episodes.

\section{Clinical Course after RTX Treatment}

The 5 patients' clinical courses after the start of the RTX infusions are shown in table 2. All patients were able to discontinue PSL usage at a median of 79 days after the 
Table 1. Patients' characteristics in children with refractory NS

\begin{tabular}{|c|c|c|c|c|c|c|c|}
\hline Patient No. & Gender & $\begin{array}{l}\text { Age at NS } \\
\text { onset, years }\end{array}$ & $\begin{array}{l}\text { Renal } \\
\text { histology }\end{array}$ & $\begin{array}{l}\text { Duration of } \\
\text { follow-up before } \\
\text { RTX, years }\end{array}$ & $\begin{array}{l}\text { Relapses before } \\
\text { RTX, n } \\
\text { (episodes/year) }\end{array}$ & $\begin{array}{l}\text { Age at } \\
\text { starting RTX, } \\
\text { years }\end{array}$ & $\begin{array}{l}\text { Immunosuppressive agents before RTX } \\
\text { (total administered period, years) }\end{array}$ \\
\hline 2 & $\mathrm{M}$ & 3.8 & MCD & 7.1 & $10(1.4)$ & 10.9 & PSL (6.4), CsA (4.7), MZB (2.1), MMF (3.1) \\
\hline 3 & $\mathrm{~F}$ & 11.1 & MCD & 5.9 & $12(2.0)$ & 17.00 & PSL (5.5), CsA (4.8), MZB (4.5), AZP (3.5) \\
\hline 4 & $\mathrm{~F}$ & 15.00 & MCD & 0.9 & $3(3.5)$ & 15.8 & PSL (0.8), CsA (0.5), MZB (0.2) \\
\hline Median & & 8.1 & & 6.3 & $8(1.4)$ & 14.4 & \\
\hline Minimum & & 1.9 & & 0.9 & $3(1.0)$ & 10.3 & \\
\hline Maximum & & 15.00 & & 8.4 & $12(3.5)$ & 17.00 & \\
\hline
\end{tabular}

Table 2. Clinical courses after RTX infusion in children with refractory NS

\begin{tabular}{|c|c|c|c|c|c|c|c|}
\hline 2 & 3.5 & 0.23 & 0.00 & 31 & $10(1.4)$ & $0(0)$ & 2.2 \\
\hline 3 & 3.2 & 0.80 & 0.00 & 241 & $12(2.0)$ & $0(0)$ & 1.9 \\
\hline Median & 3.2 & 0.80 & 0.00 & 79 & $8(1.4)$ & $0(0)$ & \\
\hline Minimum & 1.9 & 0.23 & 0.00 & 31 & $3(1.1)$ & $0(0)$ & \\
\hline Maximum & 3.8 & 0.96 & 0.00 & 241 & $12(3.5)$ & $0(0)$ & \\
\hline
\end{tabular}

start of the infusions and they could also decrease the number of administered immunosuppressants.

As shown in table 3, complete B-cell depletion was achieved in 4 patients with MCD out of the 5 subjects (80\%): in 1 patient (patient 5 with FSGS), B cells decreased but were not depleted. The disease in all patients remained in remission for a median of 2.2 years after their first RTX infusions. However, three relapses occurred in 3 patients (patients 2-4) following the start of RTX (the period from starting RTX to relapse was 2.2, 1.9, and 2.3 years, respectively); all of these relapses developed in parallel with the re-emergence of B cells. In these patients, remissions could be introduced by PSL within 10 days and have never received further RTX. Furthermore, discontinuation of PSL could be possible while it was not achieved before RTX treatment, suggesting that the administration of RTX improves responsiveness to PSL. Interestingly, patient 5 (with FSGS) did not experience a relapse after the RTX infusion, though complete B-cell depletion was not achieved, and his steroids were discontinued on day 79 .

\section{Comparison of Clinical Indicators before and after RTX Treatment}

As shown in tables 2 and 3, the changes in the clinical indicators from before to during the 12 months after last RTX administration were as follows (median value (range)); all declined significantly ( $\mathrm{p}<0.05)$ : (1) annual number of relapses: before administration 1.4 (1.1-3.5) times/year, after administration 0.0 (0.0-0.0) times/year; (2) steroid dosage: before administration $0.80(0.23-0.96)$ $\mathrm{mg} / \mathrm{kg} / \mathrm{day}$, after administration $0.03(0.02-0.27) \mathrm{mg} / \mathrm{kg} /$ day, and (3) peripheral blood B-cell count: before administration 196.0 (94.6-371.2) counts/ $\mu \mathrm{l}$, during administration $2.72(0.920-116)$ counts/ $\mu$ l. Thus, comparing before and after the administration of RTX, the frequency 
Table 3. Changes in B-cell count and serum IgG levels in children receiving repeated RTX infusion

\begin{tabular}{|c|c|c|c|c|c|c|}
\hline Patient No. & \multicolumn{2}{|l|}{ At starting RTX } & \multicolumn{3}{|l|}{ During RTX } & $\begin{array}{l}\text { After RTX } \\
\text { recovery of B-cells }{ }^{\mathrm{b}} \text { after } \\
\text { last RTX, months }\end{array}$ \\
\hline 2 & 371.2 & 1,276 & $3.3(2.7-9.4)$ & $897(843-910)$ & 24.5 & 13.2 \\
\hline 3 & 254.0 & 688 & $0.9(0.9-1.5)$ & $585(580-589)$ & 19.8 & 9.7 \\
\hline 4 & 196.0 & 428 & $1.8(1.6-1.8)$ & $517(476-532)$ & 24.3 & 12.4 \\
\hline Median & 196.0 & 688 & 2.1 & 733 & 23.4 & 11.8 \\
\hline Minimum & 94.6 & 384 & 0.9 & 517 & 0.0 & 9.7 \\
\hline Maximum & 371.2 & 1,276 & 64.4 & 897 & 24.5 & 13.2 \\
\hline
\end{tabular}

CD19 = Count of CD19+ B cells. ${ }^{\text {a }}$ CD19+ cell count $<10$ counts/ $\mu$ l any time. ${ }^{b}$ Number of CD19+ cell returns to the baseline value prior to administration of RTX.

of relapses was significantly reduced and the steroid-free period was significantly extended. On the contrary, the median (range) serum IgG did not change significantly during the clinical course: before administration 688 (384-1,276) mg/dl, after RTX treatment 733 (517-897) $\mathrm{mg} / \mathrm{dl}(\mathrm{p}=0.60)$.

\section{Adverse Events}

Reactions to the infusions were observed once in $1 \mathrm{pa}-$ tient in a total of 20 times of RTX administrations for 5 patients (5\%), though it was mild respiratory distress. No serious side effects or infectious diseases that required discontinuation of the trial were seen.

\section{Discussion}

RTX, anti-CD20 monoclonal antibody, has been successfully used in the last decade to treat patients with refractory NS, including SDNS [5-16]. However, the place of RTX in the treatment of SDNS remains to be established because of the low quality of evidence according to the recently issued clinical practice guideline for kidney diseases by KDIGO (Kidney Disease: Improving Global Outcomes) [25]: it is suggested that RTX can be considered only in children with SDNS, who have continuing frequent relapses despite optimal combinations of PSL and corticosteroid-sparing agents, and/or who have serious adverse effects of therapy.

Nonetheless, case series report that RTX has considerable efficacy against childhood SDNS, although many patients tend to relapse within 1 year consistently with the re-emergence of B cells if receiving RTX at a dose of 375 $\mathrm{mg} / \mathrm{m}^{2}$ BSA once weekly for 4 weeks [5-9]. The recent investigation into SDNS demonstrated that the peripheral blood B-cell count decreased for about 100 days upon single RTX administration before NS relapsed [17]. Thus, it has been postulated that the effectiveness of RTX treatment is related to the depletion of B cells and the patients appear to be dependent on RTX with relapse after CD19+ $\mathrm{B}$-cell re-emergence. Therefore, the optimal therapeutic protocol seems to be regular repeated doses, with one infusion at the time of CD19+ B-cell re-emergence while there have been no reports of giving RTX every 3 months for children with SDNS to date.

These findings prompted us to conduct the prospective study of a repeated administration of RTX characterized by 4 times at $375 \mathrm{mg} / \mathrm{m}^{2} \mathrm{BSA} /$ time at 3-month intervals. As a result, our regimen clearly indicates that it is effective for children with SDNS because (1) all of the patients could discontinue steroids, (2) the frequency of relapses was significantly reduced, (3) the steroid-free period was significantly extended, and (4) the mean steroid dosages were significantly reduced. Furthermore, it is of note that the median time to first relapse after initiating RTX was as long as 2.1 years.

In the current study, three relapses occurred in 3 patients in parallel with the re-emergence $\left(>10\right.$ cells $\left./ \mathrm{mm}^{3}\right)$ of B cells (table 2) and that the median time to B-cell count re-emergence was as long as 11.8 months (range 9.7-13.2) after the final course of RTX (table 3). Therefore, re-dosing with RTX at 1 year after the completion of 4 times of RTX administration might be efficacious to prevent the relapses. 
Thus, our regimen with repeated administration of RTX by 4 at 3-month intervals seems to be superior to the previous regimens $[6,7]$ in terms of relapse-free interval by the induction of longer period of B-cell depletion. The mechanism(s) of action how the RTX - a chimeric monoclonal antibody directed against the CD20 antigen expressed on B-cells - prevents relapses in the children with SDNS are currently unknown. Since Shalhoub's [26] proposal that MCD is a disorder of T-cell function with release of a circulating factor inducing proteinuria about four decades ago, activated $\mathrm{T}$ cells had been thought to play a key role in its pathogenesis. Based on this concept, it has been postulated that steroid and diverse immunosuppressants induce remission and prevent relapses via their suppressive effects on T cells [1]. However, a number of recent clinical observations provided evidence of an important role for B cells in the development of NS including our study [27-29]. In fact, RTX can be effective in treating patients with refractory NS $[6,7,30]$ while it has been successfully used in patients with B-cell lymphoma and autoimmune disease such as systemic lupus erythematosus [31]. These results may imply that RTX can prevent relapses in refractory NS by attenuating Tcell function via inhibition on the interaction between $\mathrm{B}$ cells and activated $\mathrm{T}$ cells. Meanwhile, interestingly enough, recent studies demonstrated a mechanism by which the RTX prevents recurrent FSGS after kidney transplantation through a direct regulation of podocyte function $[32,33]$. As this mechanism appears to be independent on B cells, it offers further rationale to introduce RTX in treating SDNS. From that perspective it is of note that patient 5 with FSGS in the current study achieved long-term remission after the RTX infusions, although complete B-cell depletion was not achieved.

While RTX has been used in clinical settings for over 10 years for hematological malignancies, it can lead to rare but lethal adverse events, such as progressive multiple leukoencephalopathy, interstitial pneumonia, ulcerative colitis, and $P$. jirovecii pneumonia [34-36]. The most severe adverse effect reported to date is lung damage, particularly a pulmonary hemorrhage leading to death [37]. In the present study, the adverse events associated with RTX were acceptable: a mild reaction to the infusion was observed in once among 20 times of infusions (5\%). In fact, there have been no reports of progressive multiple leukoencephalopathy caused by RTX in children with NS, whereas 1 patient with SRNS died from interstitial pneumonia after RTX therapy [38]. There are also remaining doubts regarding infectious complications that could be related to hypogammaglobulinemia: it has been postulated that prolonged B-cell depletion leads to a progressive decrease in the serum $\operatorname{IgG}$ level $[9,39]$. However, we observed no significant effect of the RTXinduced B-cell depletion on serum IgG levels in agreement with the observation by Delbe-Bertin et al. [39]. Thus, it is considered that RTX is relatively well tolerated in children with NS. Nonetheless, IgG monitoring should be performed in patients with RTX-induced B-cell depletion and the effects of persistent B-cell depletion on the developing immune system in children should be carefully monitored for a long period as no sufficient data regarding the adverse effect of RTX currently exists. We also recommend that $\mathrm{CD} 19+\mathrm{B}$-cell counts should be monitored every 3 months during the RTX treatment and 3 months after the final administration and then once a month until confirming their re-emergence.

There are several limitations of the current study. First, it was a prospective one with a very small number of patients, with no placebo-controlled group, though it seems difficult to design such a study considering the established efficacy of RTX in the patients with SDNS. Second, the detailed protocols for discontinuation of PSL or administration of MMF in conjunction with RTX treatment were left to doctors in charge.

In summary, we verified that the regular repeated doses of RTX, with one infusion at the time of CD19+ B-cell re-emergence, showed better results than the previous reports of RTX for the treatment of SDNS. The effectiveness of RTX is considered to be related to the depletion of B cells and/or regulation of podocytes. The primary aim of the therapy for children with SDNS is to maintain sustained remission with reduced co-administration of immunosuppressive drugs, thereby avoiding serious side effects. Therefore, it is concluded that the repeated administration of RTX against SDNS in children may be a useful therapeutic option. Although RTX appears to have a relatively good safety profile, the question now is how long to continue RTX treatment and which treatment should be used after the discontinuation of RTX therapy.

\section{Acknowledgment}

This study was partly supported by the Mami Mizutani Foundation.

\section{Disclosure Statement}

The authors have no conflicts of interest to disclose. 


\section{References}

1 Kaneko K: Pathogenesis in childhood idiopathic nephrotic syndrome: an update of patchwork. Curr Pediatr Rev 2009;5:55-64.

-2 Fujinaga S, Kaneko K, Muto T, Ohtomo Y, Murakami H, Yamashiro Y: Independent risk factors for chronic cyclosporine-induced nephropathy in children with nephrotic syndrome. Arch Dis Child 2006;91:666-670.

-3 Kranz B, Vester U, Büscher R, Wingen AM, Hoyer PF: Cyclosporine-A-induced nephrotoxicity in children with minimal-change nephrotic syndrome: long-term treatment up to 10 years. Pediatr Nephrol 2008;23:581-586.

$\checkmark 4$ Latta K, von Schnakenburg C, Ehrich JH: A meta-analysis of cytotoxic treatment for frequently relapsing nephrotic syndrome in children. Pediatr Nephrol 2001;16:271-282.

$\checkmark 5$ Benz K, Dötsch J, Rascher W, Stachel D: Change of the course of steroid-dependent nephrotic syndrome after rituximab therapy. Pediatr Nephrol 2004;19:794-797.

6 Gilbert RD, Hulse E, Rigden S: Rituximab therapy for steroid-dependent minimal change nephrotic syndrome. Pediatr Nephrol 2006;21:1698-1700.

7 François H, Daugas E, Bensman A, Ronco P: Unexpected efficacy of rituximab in multirelapsing minimal change nephrotic syndrome in the adult: first case report and pathophysiological considerations. Am J Kidney Dis 2007;49:158-161

8 Smith GC: Is there a role for rituximab in the treatment of idiopathic childhood nephrotic syndrome? Pediatr Nephrol 2007;22:893-898.

-9 Kemper MJ, Gellermann J, Habbig S, Krmar RT, Dittrich K, Jungraithmayr T, Pape L, Patzer L, Billing H, Weber L, Pohl M, Rosenthal K, Rosahl A, Mueller-Wiefel DE, Dötsch J: Long-term follow-up after rituximab for steroid-dependent idiopathic nephrotic syndrome. Nephrol Dial Transplant 2012;27: 1910-1915.

10 Dallachio IA, Trimoreau F, Feuillard J, Guigoinis V: A case of steroid-dependent nephrotic syndrome treated with rituximab (abstract). Pediatr Nephrol 2006;21:1615.

11 Hofstra JM, Deegens JK, Wetzels JF: Rituximab: effective treatment for severe steroiddependent minimal change nephrotic syndrome? Nephrol Dial Transplant 2007;22: 2100-2102.

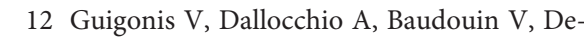
hennault M, Hachon-Le Camus C, Afanetti M, Groothoff J, Llanas B, Niaudet P, Nivet H Raynaud N, Taque S, Ronco P, Bouissou F: Rituximab treatment for severe steroid- or cyclosporine-dependent nephrotic syndrome: a multicentric series of 22 cases. Pediatr Nephrol 2008;23:269-279.

13 Bagga A, Sinha A, Moudgil A: Rituximab in patients with the steroid-resistant nephrotic syndrome. N Engl J Med 2007;356:27512752.

14 Nakayama M, Kamei K, Nozu K, Matsuoka K, Nakagawa A, Sako M, Iijima K: Rituximab for refractory focal segmental glomerulosclerosis. Pediatr Nephrol 2008;23:481-485.

15 Yang T, Nast CC, Vo A, Jordan SC: Rapid remission of steroid and mycophenolate mofetil-resistant minimal change nephrotic syndrome after rituximab therapy. Nephrol Dial Transplant 2008;23:377-380.

16 Suri M, Tran K, Sharma AP, Filler G, Grimmer J: Remission of steroid-resistant nephrotic syndrome due to focal and segmental glomerulosclerosis using rituximab. Int Urol Nephrol 2008;40:807-810.

17 Kamei K, Ito S, Nozu K, Fujinaga S, Nakayama M, Sako M, Saito M, Yoneko M, Iijima K: Single dose of rituximab for refractory steroid-dependent nephrotic syndrome in children. Pediatr Nephrol 2009;24:13211328.

18 ISKDC: The primary nephrotic syndrome in children. Identification of patients with minimal change nephrotic syndrome from initial response to prednisone. A report of the International Study of Kidney Disease in Children. J Pediatr 1981;98:561-564.

19 Gipson DS, Massengill SF, Yao L, Nagaraj S, Smoyer WE, Mahan JD, Wigfall D, Miles P, Powell L, Lin JJ, Trachtman H, Greenbaum LA: Management of childhood-onset nephrotic syndrome. Pediatrics 2009;124:747-757.

-20 Foran JM, Rohatiner AZ, Cunningham D, Popescu RA, Solal-Celigny P, Ghielmini M, Coiffier B, Johnson PW, Gisselbrecht C, Reyes F, Radford JA, Bessell EM, Souleau B, Benzohra A, Lister TA: European phase II study of rituximab (chimeric anti-CD20 monoclonal antibody) for patients with newly diagnosed mantle-cell lymphoma and previously treated mantle-cell lymphoma, immunocytoma, and small B-cell lymphocytic lymphoma. J Clin Oncol 2000;18:317324.

21 Armitage JD, Montero C, Benner A, Armitage JO, Bociek G: Acute coronary syndromes complicating the first infusion of rituximab. Clin Lymphoma Myeloma 2008;8:253-255.

22 Poterucha JT, Westberg M, Nerheim P, Lovell JP: Rituximab-induced polymorphic ventricular tachycardia. Tex Heart Inst J 2010;37: 218-220.

23 Hiraga J, Kondoh Y, Taniguchi H, Kinoshita T, Naoe T: A case of interstitial pneumonia induced by rituximab therapy. Int J Hematol 2005;81:169-170.

24 Hardak E, Oren I, Dann EJ, Yigla M, Faibish T, Rowe JM, Avivi I: The increased risk for pneumocystis pneumonia in patients receiving rituximab-CHOP-14 can be prevented by the administration of trimethoprim/sulfamethoxazole: a single-center experience. Acta Haematol 2012;127:110-114.

25 Kidney Disease: Improving Global Outcomes (KDIGO) Glomerulonephritis Work Group: KDIGO Clinical practice guideline for glomerulonephritis. Kidney Int 2012;2 (suppl):139-274.
26 Shalhoub RJ: Pathogenesis of lipoid nephrosis: a disorder of T-cell function. Lancet 1974; 2:556-560.

27 Grimbert P, Audard V, Remy P, Lang P, Sahali D: Recent approaches to the pathogenesis of minimal-change nephrotic syndrome. Nephrol Dial Transplant 2003;18:245-248.

28 Kemper MJ, Meyer-Jark T, Lilova M, MüllerWiefel DE: Combined T- and B-cell activation in childhood steroid-sensitive nephrotic syndrome. Clin Nephrol 2003;60:242-247.

29 Iharada A, Kaneko K, Tsuji S, Hasui M, Kanda S, Nishiyama T: Increased nitric oxide production by $\mathrm{T}$ and $\mathrm{B}$ cells in idiopathic nephrotic syndrome. Pediatr Nephrol 2009;24: 1033-1038.

30 Sellier-Leclerc AL, Macher MA, Loirat C Guerin V, Watier H, Peuchmaur M, Baudouin V, Deschenes G: Rituximab efficiency in children with steroid-dependent nephrotic syndrome. Pediatr Nephrol 2010;25:1109-1115.

- 31 Haffner D, Fischer DC: Nephrotic syndrome and rituximab: facts and perspectives. Pediatr Nephrol 2009;24:1433-1438.

32 Chan AC: Rituximab's new therapeutic target: the podocyte actin cytoskeleton. Sci Transl Med 2011;85:85ps21.

33 Fornoni A, Sageshima J, Wei C, MerscherGomez S, Aguillon-Prada R, Jauregui AN, Li J, Mattiazzi A, Ciancio G, Chen L, Zilleruelo G, Abitbol C, Chandar J, Seeherunvong W, Ricordi C, Ikehata M, Rastaldi MP, Reiser J, Burke GW 3rd: Rituximab targets podocytes in recurrent focal segmental glomerulosclerosis. Sci Transl Med 2011;85:85ra46.

- 34 Teichmann LL, Woenckhaus M, Vogel C, Salzberger B, Scholmerich J, Fleck M: Fatal Pneumocystis pneumonia following rituximab administration for rheumatoid arthritis. Rheumatology 2008;47:1256-1257.

35 Kumar D, Gourishankar S, Mueller T, Cockfield S, Weinkauf J, Vethanayagam D, Humar A: Pneumocystis jirovecii pneumonia after rituximab therapy for antibody-mediated rejection in a renal transplant recipient. Transpl Infect Dis 2009;11:167-170.

-36 Shelton E, Yong M, Cohney S: Late onset Pneumocystis pneumonia in patients receiving rituximab for humoral renal transplant rejection. Nephrology 2009;14:96-99.

37 Alexandrescu DT, Dutcher JP, O’Boyle K, Albulak M, Oiseth S, Wiernik PH: Fatal intraalveolar hemorrhage after rituximab in a patient with non-Hodgkin lymphoma. Leuk Lymphoma 2004;45:2321-2325.

38 Chaumais MC, Garnier A, Chalard F, Peuchmaur M, Dauger S, Jacqz-Agrain E, Deschênes G: Fatal pulmonary fibrosis after rituximab administration. Pediatr Nephrol 2009;24:1753-1755.

-39 Delbe-Bertin L, Aoun B, Tudorache E, Lapillone $\mathrm{H}$, Ulinski T: Does rituximab induce hypogammaglobulinemia in patients with pediatric idiopathic nephrotic syndrome? Pediatr Nephrol 2013;28:447-451. 